\title{
Modulation of Mutant Huntingtin N-Terminal Cleavage and Its Effect on Aggregation and Cell Death
}

\author{
Katrin Juenemann • Christina Weisse • \\ Denise Reichmann • Christoph Kaether • \\ Cornelis F. Calkhoven · Gabriele Schilling
}

Received: 18 July 2010/Revised: 14 October 2010/Accepted: 27 October 2010/Published online: 30 November 2010

(C) The Author(s) 2010. This article is published with open access at Springerlink.com

\begin{abstract}
Huntington's disease (HD) is a neurodegenerative disorder caused by a polyglutamine expansion near the N-terminus of huntingtin. A neuropathological hallmark of Huntington's disease is the presence of intracellular aggregates composed of mutant huntingtin $\mathrm{N}$-terminal fragments in human postmortem brain, animal models, and cell culture models. It has been found that $\mathrm{N}$-terminal fragments of the mutant huntingtin protein are more toxic than the full-length protein. Therefore, proteolytic processing of mutant huntingtin may play a key event in the pathogenesis of HD. Here, we present evidence that the region in huntingtin covering amino acids 116 to 125 is critical for $\mathrm{N}$-terminal proteolytic processing. Within this region, we have identified mutations that either strongly reduce or enhance $\mathrm{N}$-terminal cleavage. We took advantage of this effect and demonstrate that the mutation $\Delta 121-122$ within the putative cleavage region enhances $\mathrm{N}$-terminal cleavage of huntingtin and the aggregation of $\mathrm{N}$-terminal fragments. Furthermore, this particular deletion increased the activation of apoptotic processes and decreased neuronal cell viability. Our data indicate that the $\mathrm{N}$-terminal proteolytic processing of mutant huntingtin can be modulated with an effect on aggregation and cell death rate.
\end{abstract}

K. Juenemann - C. Weisse - D. Reichmann - C. Kaether .

C. F. Calkhoven - G. Schilling

Leibniz Institute for Age Research, Fritz Lipmann Institute,

07745 Jena, Germany

K. Juenemann $(\square)$

Department of Cell Biology and Histology, Academic Medical

Center, University of Amsterdam, Meibergdreef 15,

M3-105, 1105 AZ Amsterdam, The Netherlands

e-mail: K.Junemann@amc.uva.nl
Keywords Huntington's disease · Huntingtin · Polyglutamine $\cdot$ Proteolytic processing $\cdot$ N-terminal fragment

\section{Introduction}

Huntington's disease (HD) is an autosomal-dominant inherited, progressive and fatal neurodegenerative disorder caused by expansion of a CAG repeat in the huntingtin gene, coding for polyglutamine (polyQ) (The Huntington's Disease Collaborative Research Group 1993; Ross et al. 1997). The expansion of the polyQ stretch in the huntingtin protein (htt) to a length greater than 36 consecutive glutamines is causing HD. The onset of disease usually occurs in mid-adult life and lasts 15-25 years. Symptoms of HD include involuntary movements, cognitive impairment, and psychiatric disturbances (Vonsattel and DiFiglia 1998). Despite widespread expression of the huntingtin gene (Sharp et al. 1995), there is a selective vulnerability and loss of the medium spiny projection neurons in the striatum (Vonsattel et al. 1985).

Transgenic or knock-in mice that express full-length or truncated mutant htt (mhtt) display a neurological phenotype resembling HD with intracellular inclusions (Davies et al. 1997; Hodgson et al. 1999; Reddy et al. 1998; Schilling et al. 1999; Tanaka et al. 2006; Wheeler et al. 2000). Postmortem analysis of brains from HD patients and studies using mouse or cell culture HD models revealed that nuclear and cytoplasmic inclusions contain $\mathrm{N}$-terminal fragments of mhtt (DiFiglia et al. 1997; Gutekunst et al. 1999; Lunkes et al. 2002; Schilling et al. 2007). Moreover, pathological changes are accelerated in HD mouse models overexpressing mhtt $\mathrm{N}$-terminal fragments compared to those with full-length mhtt (Hodgson et al. 1999; 
Mangiarini et al. 1996; Schilling et al. 1999; Wheeler et al. 2000). One exception is observed with the HD mouse model expressing the first 117 amino acids (aa) of mhtt showing neuronal inclusions but no behavioral abnormalities or neurodegeneration (Slow et al. 2005). Since the correlation between formation of inclusions and neuronal cell death is weak (Gutekunst et al. 1999; Kuemmerle et al. 1999; Saudou et al. 1998), the role of inclusions in HD pathogenesis is not clear. Accumulated evidence suggest that the oligomeric intermediates of mhtt fragments cause cytotoxicity (Arrasate et al. 2004; Ross and Poirier 2005; Sanchez et al. 2003).

Htt can be cleaved between residues 400 and 600 at several sites by caspases, calpains, and MMP-10 (Gafni and Ellerby 2002; Goldberg et al. 1996; Kim et al. 2001; Miller et al. 2010; Wellington et al. 2002), which may contribute to toxicity (Gafni et al. 2004; Graham et al. 2006; Wellington et al. 2000). In addition, smaller N-terminal fragments of htt than those generated by caspase or calpain cleavage are found in human HD postmortem brain (DiFiglia et al. 1997; Lunkes et al. 2002) or in mouse models of HD (Li et al. 2000; Schilling et al. 2007). At least two smaller $\mathrm{N}$-terminal fragments, called cp-A and cp-B, have been described (Kim et al. 2006; Lunkes et al. 2002). Deletion of aa 104-114 prevented release of cp-A and the production of the longer cp-B cleavage product was reduced after deletion of aa 205-214. The release of cp-A and cp-B can be inhibited by pepstatin, suggesting that the protease(s) responsible for the generation of the htt $\mathrm{N}$-terminal cp-A and cp-B belong to the family of aspartyl endopeptidases. In addition, short $\mathrm{N}$-terminal fragments $(\mathrm{Cp}-1$ and $\mathrm{Cp}-2)$ can be released by caspase independent proteolytic cleavage of htt in a PC12 cell model expressing full-length mhtt (Ratovitski et al. 2007). Recent studies identified the length of two short htt $\mathrm{N}$-terminal cleavage products. In the $H d h \mathrm{Q} 150$ knock-in mouse model htt exon 1 was identified as the smallest cleavage product with a length of 90 aa (Landles et al. 2010) and in vitro studies suggest htt cleavage at position 167 (generating the fragment cp-2) (Ratovitski et al. 2009).

The proteolytic pathways that generate short htt N-terminal cleaved fragments are still poorly understood. A better understanding of htt proteolytic processing provides important insights in the early mechanisms of HD pathogenesis and will lead to the development of new HD therapeutics. Our previous work showed that in the HD N171-18Q, -44Q, and -82Q mouse model, cleavage of htt appears to be a normal process (Schilling et al. 1999). We have recently detected an N-terminal fragment of mhtt in the HD N171-82Q mouse model and in human HD postmortem brain lacking the epitope 115-129 (Schilling et al. 2007) and being similar to cp-A detected in NG108-15 cells expressing mhtt (Lunkes et al. 2002).
Using an in vitro cell culture model, we have now identified a region between aa 116-125 in htt where the efficiency of N-terminal cleavage is strongly affected by mutations with the cleavage either being suppressed or enhanced. The mutation $\Delta 121-122$ that enhances cleavage, and hence mhtt $\mathrm{N}$-terminal fragment release results in increased aggregation, apoptotic processes and in a decrease of neuronal cell viability. Our data show that the $\mathrm{N}$-terminal cleavage of mhtt can be modulated with an effect on aggregation and cell death rate.

\section{Materials and Methods}

\section{Vector Construction}

Expression constructs containing htt cDNA encoding the first 171 (N171) and 233 (N233) amino acids with 18 glutamines (wild-type htt) or 82 glutamines (mhtt) were cloned into pcDNA3.1 or pRC/CMV, whereas the numbering of amino acids is based on wild-type htt sequence with 23 repeats. Addition of the myc-epitope tag at the C-terminus of htt-N171-18Q and generation of shorter htt constructs by introduction of translational termination codon into htt-N171-18Q at aa 116 or 121 were performed by PCR amplification. The $5^{\prime}$ primer for producing htt-N171-18Q-myc incorporated a c-myc epitope and an $E c o$ RI site in its $5^{\prime}$ end. In the $3^{\prime}$ end of the $3^{\prime}$ primer, an $X b a \mathrm{I}$ site was incorporated. The primers for generating stop codons in htt-N171-18Q included BamHI restriction sites. PCR products were digested and subcloned into similarly digested pcDNA3.1. Site-directed mutagenesis was performed by using the QuikChange II kit (Stratagene), according to manufacturer's protocol. All htt expression constructs and CAG repeat lengths were confirmed by DNA sequencing.

\section{Cell Culture and Transfection}

HEK 293 (human embryonic kidney) cells, HeLa (human cervical carcinoma) cells, COS-7 (monkey kidney) cells and N2a (mouse neuroblastoma) cells were cultured in Dulbecco's modified Eagle's medium (DMEM) with high glucose, stable glutamine and supplemented with $10 \%$ fetal calf serum (FCS) and $1 \%$ penicillin/streptomycin at $37^{\circ} \mathrm{C}$ with $5 \% \mathrm{CO}_{2}$. STHdh ${ }^{+} / H d h^{+}$cells (mouse striatal precursors) were grown at $33^{\circ} \mathrm{C}$ in DMEM with $10 \%$ FCS and a selection by G418 for selection (Trettel et al. 2000). All cell culture reagents were obtained from PAA laboratories, Austria. Cells were transiently transfected with htt constructs using Lipofectamine ${ }^{\mathrm{TM}} 2000$ (Invitrogen). Cells were seeded $24 \mathrm{~h}$ before transfection in six-well plates and incubated with a mixture of $6 \mu \mathrm{g}$ DNA and $12 \mu \mathrm{l}$ 
Lipofectamine $^{\mathrm{TM}} 2000$ for $48 \mathrm{~h}$. Cell viability of N2a cells was assessed $48 \mathrm{~h}$ after transfection by trypan blue dye solution (Sigma). Transfected N2a cells were resuspended in culture medium containing $0.1 \%$ trypan blue dye solution and examined by light microscopy. Viable and nonviable cells were then counted, and the score obtained expressed vital cells in percent of total cells.

\section{Antibodies}

The polyclonal antibody N18 (sc-8767), the monoclonal antibody c-myc 9E10 (sc-40) and the $\beta$-actin monoclonal antibody (sc-47778) were purchased from Santa Cruz Biotechnology. The $\beta$-tubulin monoclonal antibody (GTX11307) is from GeneTex and the cytochrome c monoclonal antibody (7H8.2C12) is from BioVision. Different antibodies were used to detect various regions of the htt protein, whereas the monoclonal antibodies 1C2 (MAB1574) and anti-huntingtin 115-129 (MAB5490) were purchased from Chemicon International. Peptide-specific antibodies designated htt 55-66 and htt 81-90 were described previously (Schilling et al. 2007). Peptide sequences are numbered on wild-type human htt with $23 \mathrm{Q}$ (GenBank Accession Number NM_002111).

\section{Immunoblot Analysis}

Transfected cells were harvested in PBS, centrifuged and cell pellets were resuspended in lysis buffer $(50 \mathrm{mM}$ Tris$\mathrm{HCl} \mathrm{pH} 7.4,150 \mathrm{mM} \mathrm{NaCl}, 1 \mathrm{mM}$ EDTA, $1 \%$ Triton $\mathrm{X}-100$ and a cocktail of protease inhibitors), followed by sonification. The whole cell protein concentration was determined by using the bradford method (Biorad). Lysates were resolved by SDS-PAGE on 10 and $15 \%$ Tris-HCl acrylamide gels. Proteins were transferred to nitrocellulose membranes, blocked with 5\% milk powder in PBS and incubated with different primary antibodies (see above) overnight at $4^{\circ} \mathrm{C}$. Immunoblots were developed with peroxidase-conjugated secondary antibodies (Pierce) and detected by using ECL western blotting substrate (Pierce).

\section{Immunofluorescence}

COS-7 and N2a cells were grown on glass coverslips and transiently transfected with mhtt constructs as described above. $48 \mathrm{~h}$ after transfection, cells were washed with PBS and fixed for $20 \mathrm{~min}$ at $-20^{\circ} \mathrm{C}$ in methanol. Cells were blocked with $1 \%$ BSA and $2 \%$ FCS in PBS for 20 min at room temperature after three times of washing with PBS. Primary antibodies were diluted (1:1500 for htt 81-90 and 1:200 for htt 115-129) in blocking buffer and slides were incubated with the primary antibody for $45 \mathrm{~min}$ at room temperature and then washed with PBS. Secondary antibodies conjugated to Alexa Fluor 488 or Alexa Fluor 594 were added at a 1:300-1:400 dilution for $45 \mathrm{~min}$ at room temperature. Cells were washed three times with PBS, counterstained with DAPI (4',6-diamidino-2-phenylindole, Sigma) and mounted onto slides. Immunofluorescence was observed using a Zeiss Axiovert 200 Apotome and images were colourized and merged using the Adobe-Photoshop software. Aggregate formation was manually counted by examining 200 cells per coverslip after transfection. Aggregates were defined as a clearly encompassed region of dense htt staining. Cells containing several aggregates of any size were considered to have one aggregate.

\section{Cleavage Product Quantitation}

Both blotting and imaging with the Odyssey infrared imaging system (LI-COR) were performed according to manufacturer's instruction. The HEK 293 cell lysates were fractionated on $10 \%$ SDS-PAGE-gels, transferred to nitrocellulose membranes and probed with the primary antibody htt 55-66. For detection, anti-rabbit Alexa Fluor 680 antibody (Invitrogen) was added.

\section{Filter Retardation Assay}

For the filter retardation assay protein extracts were diluted with $2 \%$ SDS and $8 \% \beta$-mercaptoethanol in PBS, heated at $100^{\circ} \mathrm{C}$ for $5 \mathrm{~min}$ and filtered through a cellulose acetate membrane $(0.2 \mu \mathrm{m}$ pore size, Schleicher \& Schuell) using a MiniFold-1 Dot-Blot System (Whatman) after equalization concerning the main protein product by protein quantitation. Membrane was washed with water and subjected to the general procedure of immunoblot analysis by using an anti-htt antibody as described above.

\section{Apoptosis Assays}

Apoptosis was assessed $48 \mathrm{~h}$ after transfection of HEK 293 cells by analysis of caspase 3 and caspase 7 activities using the Caspase-Glo ${ }^{\mathrm{TM}} 3 / 7$ assay kit (Promega) according to manufacturer's protocol. After incubation at room temperature for $3 \mathrm{~h}$, luminescence was measured using a Mithras LB 940 Multilabel Reader (Berthold Technologies). Each sample was measured in triplicate and blank values were substracted. Cytochrome c release into the cytosol was assessed $48 \mathrm{~h}$ after transfection of HEK 293 cells. Mitochondrial and cytoplasmic fractions were separated using the Cytochrome c Releasing Apoptosis Assay Kit (BioVision).

Statistical Analysis

All values were obtained from at least three independent repeated experiments and expressed as mean $\pm \mathrm{SD}$. 
Statistical analysis was performed using Student's $t$ test. $P<0.05$ was considered statistically significant.

\section{Results}

\section{N-Terminal Proteolysis of Htt in Cell Culture}

To analyze the N-terminal proteolytic processing of human htt, we transiently transfected HEK 293 cells with expression plasmids encoding the first N-terminal 171 and 233 aa with 18 or 82 glutamines (see Fig. 1a for scheme of used constructs). Immunoblot analysis of whole cell extracts using the antibody htt 81-90 (Schilling et al. 2007) revealed expression of htt-N171-18Q and htt-N233-18Q. In addition to the uncleaved htt-N171-18Q and htt-N233-18Q proteins, smaller htt fragments with equal size were detected in both lanes (Fig. 1b, arrow). To examine if these smaller fragments were generated independently of polyQ length, we compared the expression from htt-N171-82Q and htt-N233-82Q constructs in HEK 293 cells. In both cases, a smaller fragment could be observed in addition to the uncleaved htt protein product on immunoblot using the antibody htt 81-90 (Fig. 1c, arrow). Interestingly, the cleavage of htt-N233-82Q seems to be much more efficient compared to htt-N171-82Q. To test if the observed smaller htt fragment is an N-terminal cleavage product, we transfected HEK 293 cells with the construct htt-N171-18Qmyc containing a myc-tag at the $\mathrm{C}$-terminus and analyzed cell lysates by SDS-PAGE and immunoblotting. The antibody htt 81-90 detected the truncated htt-N171-18Q-myc protein at the expected size of around $30 \mathrm{kDa}$ and the approximately $10 \mathrm{kDa}$ smaller cleavage product (Fig. 1d). In contrast, the anti-c-myc antibody detected the uncleaved htt protein product only, indicating that the lower protein band represents an $\mathrm{N}$-terminal cleavage product. To exclude the possibility that $\mathrm{N}$-terminal htt proteolytic processing is specific for HEK 293 cells, we investigated if the identical fragment was also observed in other non-neuronal and neuronal cell lines. Transfection of HEK 293, HeLa, COS-7, STHdh ${ }^{+} / H_{d h}{ }^{+}$and N2a cells with htt-N233-82Q followed by immunostaining with the antibodies 1C2 and htt 81-90 showed a similar N-terminal cleavage fragment (arrows) in all tested cell lines (Fig. 1e, f). These data suggest that cleavage occurs at a specific region within htt and identical proteases may act to generate the N-terminal fragment of similar size in different cell types.

\section{Distinct Nuclear and Cytoplasmatic Aggregate} Formation in Cells Expressing Mhtt

To analyze the subcellular localization of htt-N233-82Q and its N-terminal fragment, double immunofluorescence studies were performed $48 \mathrm{~h}$ after transfection of COS-7 cells with htt-N233-82Q expression plasmids. Using antibodies selectively detecting $\mathrm{N}$-terminal htt epitopes at aa 81-90 and aa 115-129, immunofluorescence studies
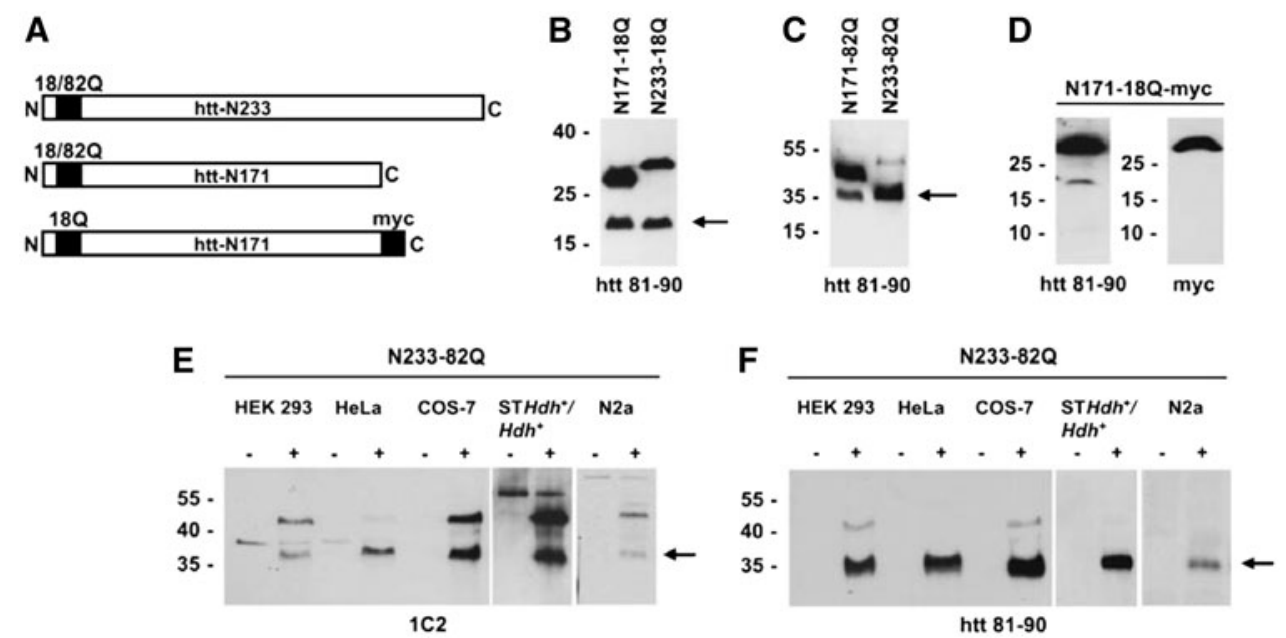

Fig. 1 N-terminal proteolytic cleavage of htt in non-neuronal and neuronal cells. a Schematic diagrams of htt constructs used. b Expression of htt-N171-18Q and htt-N233-18Q in HEK 293 cells. Immunoblot was probed with the antibody htt $81-90$ and cleavage products are indicated by an arrow. c Immunoblot of transfected HEK 293 cells expressing htt-N171-82Q and htt-N233-82Q using the antibody htt 81-90. mhtt cleavage fragments with $82 \mathrm{Q}$ were detected (arrow). d HEK 293 cells were transfected with the construct httN171-18Q-myc (C-terminal myc-epitope tag). The anti-c-myc antibody was able to detect the main htt protein band and not the $\mathrm{N}$-terminal fragment. As control htt-N171-18Q-myc extract was probed with the antibody htt 81-90 for detection of the smaller $\mathrm{N}$-terminal cleavage product. e, $\mathbf{f}$ mhtt processing in various cell lines. Immunoblots of protein extracts from nontransfected $(-)$ and httN233-82Q-transfected (+) HEK 293, HeLa, COS-7, STHdh ${ }^{+} / H d h^{+}$, and $\mathrm{N} 2 \mathrm{a}$ cells. After $48 \mathrm{~h}$, cells were lysed and analyzed by immunoblot with the antibodies e $1 \mathrm{C} 2$ and f htt 81-90. A similar mhtt $\mathrm{N}$-terminal fragment was detected in all cell lines (arrows) 
Fig. 2 N-terminal mhtt aggregates in COS-7 cells. a Transiently transfected COS-7 cells expressing htt-N233-82Q exhibit perinuclear (row 1) and nuclear (row 2, arrowhead) inclusions stained with the $\mathrm{N}$-terminal antibodies htt $81-90$ and htt 115-129 or with the antibody htt 81-90 only (row $3-4$, arrow). Scale bars are $20 \mu \mathrm{m}$. b Distribution of mhtt aggregates in COS-7 cells expressing htt-N233-82Q.

Transfected cells with aggregates stained by the antibodies htt 81-90 and htt 115-129 or htt 81-90 alone were counted per coverslip in independent experiments $(n=3)$
A
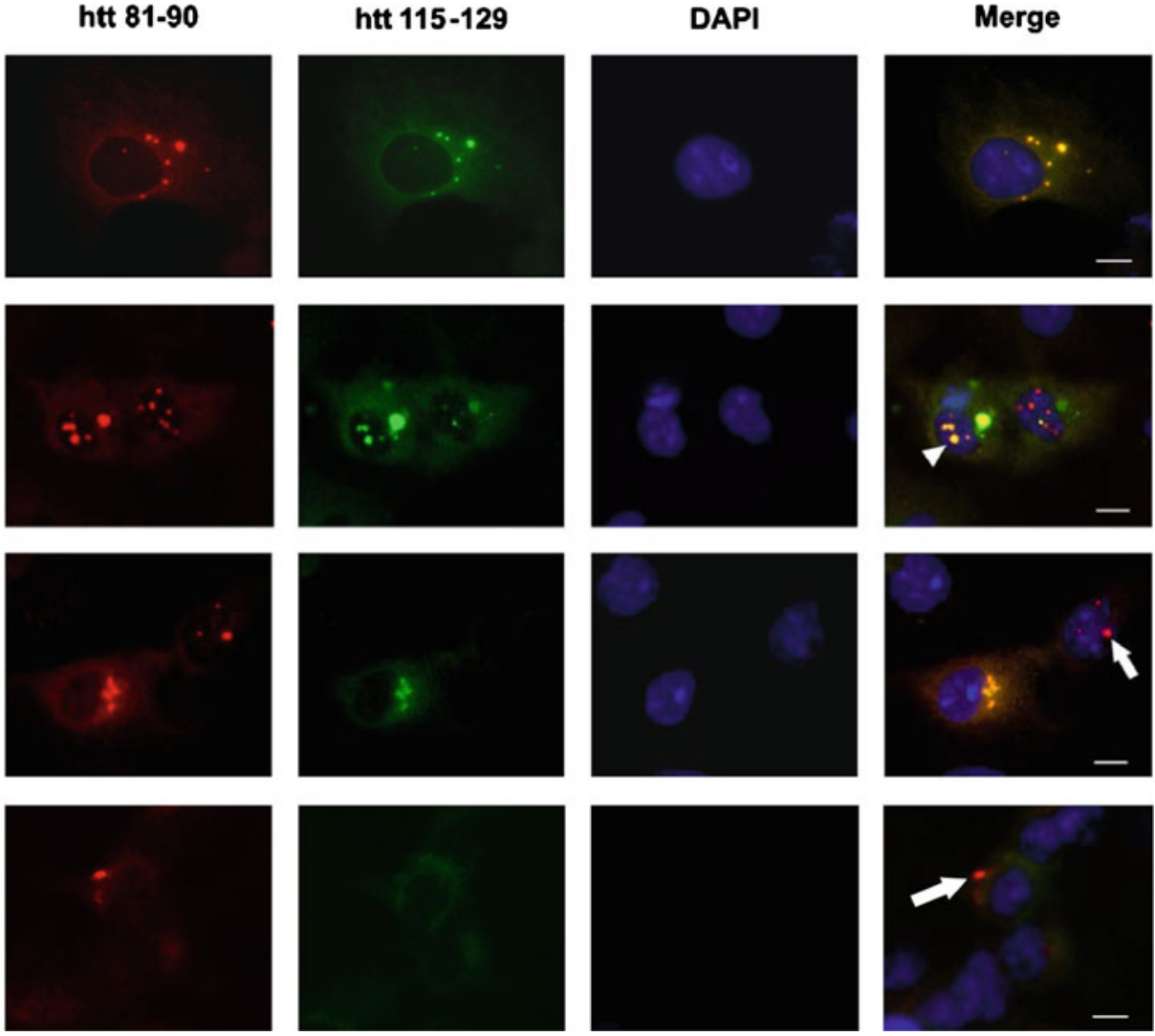

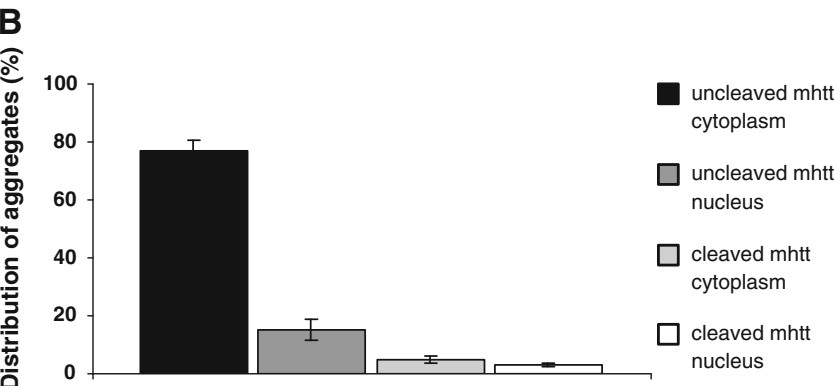

revealed cytoplasmic and nuclear inclusions containing aggregated mhtt (Fig. 2a, row 1-4). Htt-N233-82Q-derived aggregates detected with both htt $\mathrm{N}$-terminal antibodies resulted in co-localized staining in the perinuclear region (Fig. 2a, row 1) and in the nucleus (Fig. 2a, row 2, arrowhead). In addition, staining with both htt N-terminal antibodies demonstrated mhtt perinuclear and nuclear inclusions only detected by the antibody htt 81-90 lacking the epitope aa 115-129 (Fig. 2a, row 3-4, arrow). Counting of inclusions detected by the antibodies htt 81-90 and htt 115-129 revealed that $77 \%$ of htt aggregates are perinuclear and $15 \%$ nuclear localized (Fig. 2b). A few inclusions detected by the antibody htt 81-90 and not by the antibody htt 115-129 are localized in the perinuclear region $(5 \%)$ or in the nucleus $(3 \%)$.
Hence, both uncleaved htt-N233-82Q protein and the $\mathrm{N}$-terminal cleavage fragment seem to form aggregates in the perinuclear region and in the nucleus.

Analysis of the Htt N-Terminal Fragment Indicates Cleavage Around aa 120

To map the region in htt where cleavage takes place, HEK 293 cells were transfected with htt-N233-82Q and analyzed for mhtt expression with antibodies recognizing different $\mathrm{N}$-terminal htt epitopes (depicted in Fig. 3a). On immunoblots the N-terminal antibodies N18, 1C2, htt 55-66 and htt 81-90 detected both the uncleaved htt protein product and the smaller htt cleavage fragment (Fig. 3a, arrow). By contrast, the htt antibody against epitope 115-129 did not 
Fig. 3 Mapping of htt

$\mathrm{N}$-terminal cleavage.

a Antibody mapping of mhtt

proteolytic cleavage in htt-

N233-82Q-transfected cells (+)

and as control nontransfected

cells (-). $48 \mathrm{~h}$ after

transfection, cell lysates were analyzed by immunoblot with the N-terminal htt antibodies

N18, 1C2, htt 55-66, htt 81-90, and htt 115-129. All antibodies, except htt 115-129, recognized the mhtt cleavage product (arrow) running approximately $10 \mathrm{kDa}$ lower on SDS-PAGE than the main mhtt protein product. b The N-terminal fragment of htt-N171-18Q (approximately $18 \mathrm{kDa}$ ) migrates on SDS-PAGE in the same molecular range as the protein htt-N120-18Q detected on immunoblot with the antibody htt 81-90. c The protein htt-N120-82Q, the $\mathrm{N}$-terminal cleavage fragment of htt-N233-82Q (arrow) and d of htt-FL-82Q from transfected HEK 293 cells have the same mobility on SDS-PAGE compared to the mhtt cleavage fragment from brain homogenate of HD

N171-82Q line 81 transgenic (tg) mouse (lowest arrow)

shown on immunoblot with the antibody htt 81-90

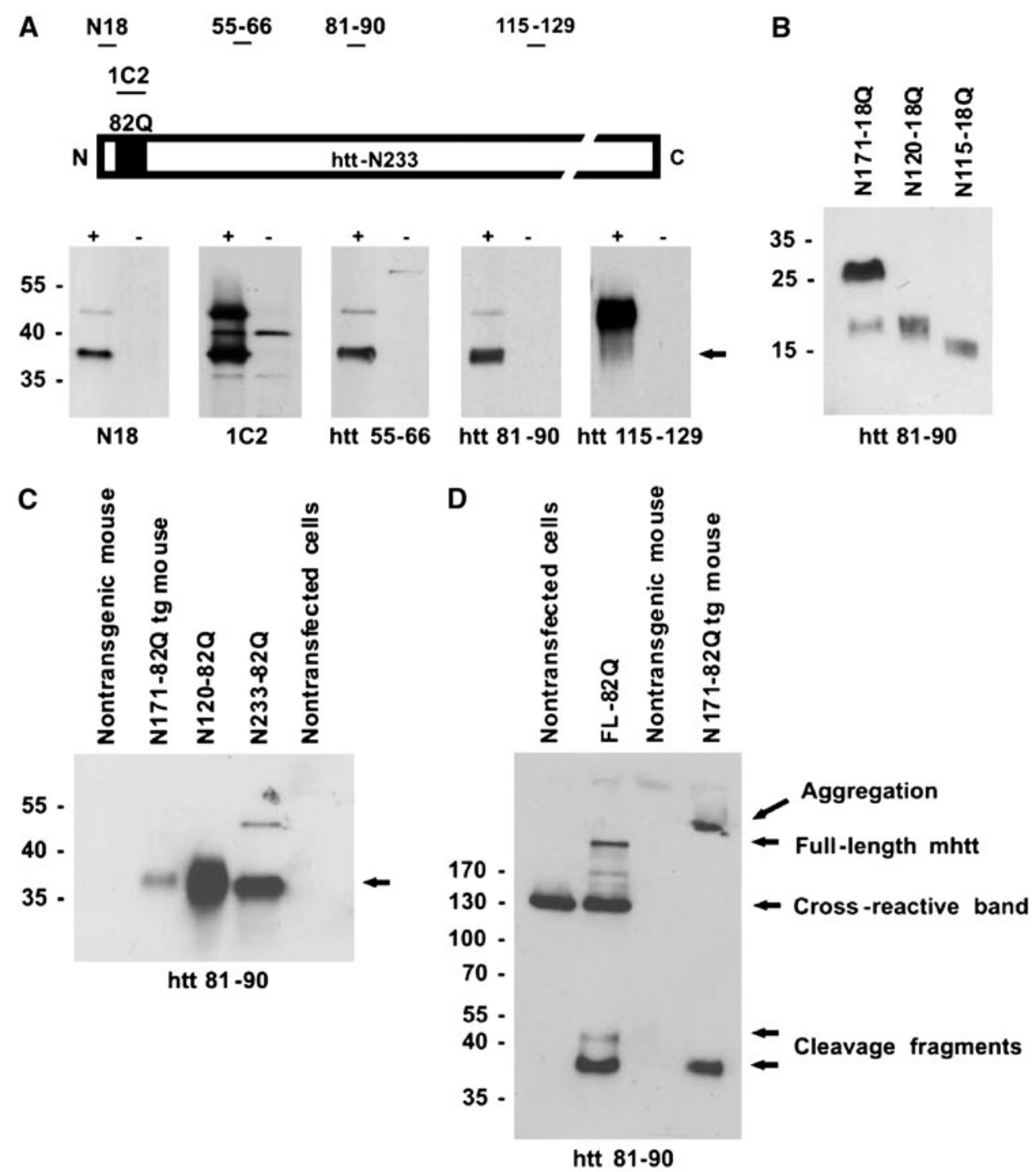

recognize the lower protein band, suggesting this epitope is either C-terminal to the cleavage site or destroyed by cleavage. These data suggest that proteolytic processing occurs between aa 90 and 129. Indeed, introduction of stop codons into htt-N171-18Q at aa 116 and 121 revealed a similar mobility of htt-N120-18Q on SDS-PAGE compared to the mobility of the $\mathrm{N}$-terminal cleavage fragment derived from htt-N171-18Q (Fig. 3b). Furthermore, the $\mathrm{N}$-terminal cleavage fragment detected in the mouse brain homogenate of HD N171-82Q line 81 transgenic mice (Schilling et al. 1999), the N-terminal cleavage fragment of htt-N233-82Q in HEK 293 cells and the protein htt-N12082Q expressed in HEK 293 cells are all in the same molecular range on SDS-PAGE (Fig. 3c, arrow). The mhtt transgenic protein product expressed in HD N171-82Q line 81 was not detectable, probably due to the inability of htt 81-90 to recognize the uncleaved htt protein. It is notably that this particular transgenic protein product can be detected by the 1C2 antibody (Schilling et al. 1999).
Expression of full-length mhtt after transfection of HEK 293 cells with htt-FL-82Q revealed on SDS-PAGE an $\mathrm{N}$-terminal cleavage fragment that was running in the same molecular range like the $\mathrm{N}$-terminal cleavage fragment derived from HD N171-82Q line 81 mice (Fig. 3d, arrow). However, a second protein band in addition to the N-terminal cleavage fragment could be detected after expression of htt-FL-82Q with the size predicted for cp-B but the signal was low. Our data suggest that proteolytic cleavage is polyglutamine length-independent and occurs around aa 120 in vitro and in vivo releasing an N-terminal fragment lacking the epitope 115-129.

Efficiency of Cleavage is Strongly Affected by Mutations within the Putative Cleavage Region

To analyze the $\mathrm{N}$-terminal cleavage region in htt more precisely, HEK 293 cells were transfected with htt-N171$18 \mathrm{Q}$ constructs containing sequential deletions of two aa in 


\section{A}

1. MATLEKLMKAFESLKSF(Q),PPPPPPPPPPPQLPQPPPQAQPLLPQPQPPPPPPPPPPGPA

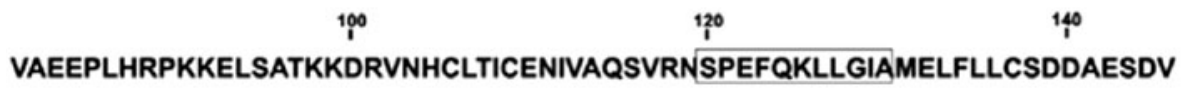

160

RMADECLNKVIKALMDSNLPRLQLE -171

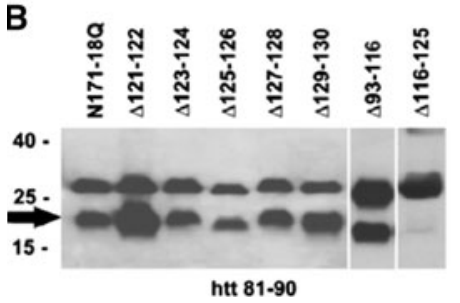

Fig. 4 Mutations within the N-terminal cleavage region of htt. a Sequence of the first 171 aa of htt is shown with the region of interest where double aa deletions or double alanine substitutions were inserted between aa 120-130 (framed). Htt-N171-18Q with b sequential two aa deletions, $\Delta 93-116, \Delta 116-125$ and c sequential substitutions with two alanines were expressed in HEK 293 cells and detected on immunoblot with the antibody htt 81-90. The N-terminal cleavage fragment is indicated by an arrow. $\Delta 121-122$ consistently

the region aa 120-130 (Fig. 4a, framed) and htt-N171-18Q constructs with two larger deletions $\Delta 93-116$ and $\Delta 116-125$, respectively. All double aa deletion mutants generated smaller N-terminal fragments (Fig. 4b, arrow) as was detected by immunostaining with the antibody htt 81-90, however, with variation in staining intensity between individual experiments and the different mutants. Notably, the mutation $\Delta 121-122$ consistently resulted in enhanced efficiency of cleavage in all repeated experiments. The larger deletion $\Delta 93-116$ had no effect on cleavage fragment formation compared to the deletion $\Delta 116-125$, which showed a strong reduction in fragment release. In addition, we analyzed htt fragment release from htt-N171-18Q mutants with sequential double substitutions into alanine in the region aa 120-130 (Fig. 4c, arrow). Here, we could identify the mutation AA124-125 with the strongest and sustained reduction in fragment release in all repeated experiments.

For further analyses, the mutations AA124-125, $\Delta 116-125$, and $\Delta 121-122$ resulting in either strong reduced or enhanced $\mathrm{N}$-terminal cleavage were used in the htt-N233-82Q background due to the fact that this protein gets more efficiently cleaved than htt-N171-82Q (Fig. 1c). The mutations AA124-125 and $\Delta 116-125$ also affected cleavage when introduced into the construct htt-N233-82Q, containing a polyQ repeat in the pathological range, with reduction of fragment formation of $3.2 \pm 0.3$-fold and $2.8 \pm 0.4$-fold $(n=3)$, respectively (Fig. $4 \mathrm{~d}$, arrow). Similarly to the mutant htt-N171-18Q $\Delta 121-122$ the mutation $\Delta 121-122$ in htt-N233-82Q results in a $2.5 \pm 0.1$-fold $(n=3)$ enhanced cleavage as revealed by quantitation of immunoblots. Interestingly, the mutation $\Delta 105-114$, previously shown to inhibit release of cp-A in NG108-15 cells (Lunkes et al. 2002), did not affect the generation of cleaved N-terminal fragment in our transfected HEK 293 cell model and in stable PC12 cells expressing full-length mhtt (Ratovitski et al. 2007). However, in NG108-15 cells cp-A was only detectable in the present of proteasome inhibitors (Lunkes et al. 2002), whereas in our cells transfected with truncated htt constructs the N-terminal fragment could be detected without proteasome inhibition.

We conclude that the htt $\mathrm{N}$-terminal region between aa 116-125 is important for cleavage in transfected HEK 293 cells. Mutations within the putative cleavage region seem to differentially affect htt cleavage efficiency independent of polyglutamine length, resulting in either a strong reduction (AA124-125) or an increase $(\Delta 121-122)$ of cleaved fragment release.

Deletion of aa 121-122 in Mhtt Results in Activation of Apoptotic Processes, Decreased Neuronal Cell Viability and Increased Aggregation

To study the cellular effect of mutations in the putative mhtt cleavage region, we transfected HEK 293 cells with htt-N233-82Q and its mutants to monitor execution of apoptotic pathways by measuring caspase 3 and caspase 7 activities using a luciferase assay (Fig. 5a). In cells expressing the mutant htt-N233-82Q $\Delta 121-122$, which produce higher amounts of $\mathrm{N}$-terminal fragment, the 

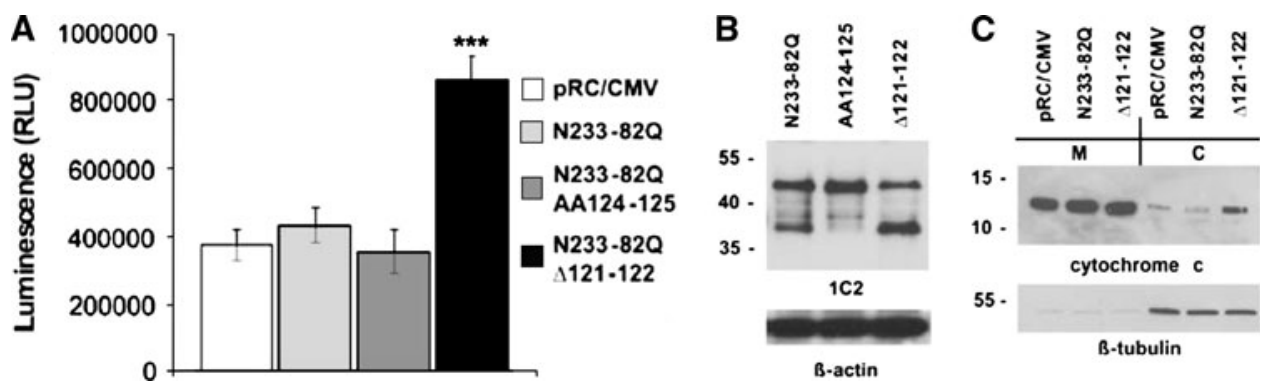

Fig. 5 Caspase 3 and caspase 7 activities in HEK 293 cells expressing mhtt. a Caspase 3 and caspase 7 activities of transfected HEK 293 cells expressing htt-N233-82Q and its mutants. Transfection of the empty vector pRC/CMV served as control. Increased activities of caspase 3 and caspase 7 are demonstrated in increased relative light units (RLU). Luminescence data were obtained $48 \mathrm{~h}$ after transfection. The difference in caspase 3 and caspase 7 activities of cells

transfected with htt-N233-82Q $\Delta 121-122$ was statistically significant compared to htt-N233-82Q $(n=3$, *** $P<0.001)$. b Immunoblot with the antibody $1 \mathrm{C} 2$ shows the expression levels of transfected mhtt constructs used for luciferase assay. c Immunoblot showing the increased level of cytochrome $\mathrm{c}$ in the cytosolic fraction of htt-N23382Q $\Delta 121-122$ transfected HEK 293 cells. The blots were probed with the antibody anti-cytochrome $c$ and the anti-ß-tubulin antibody
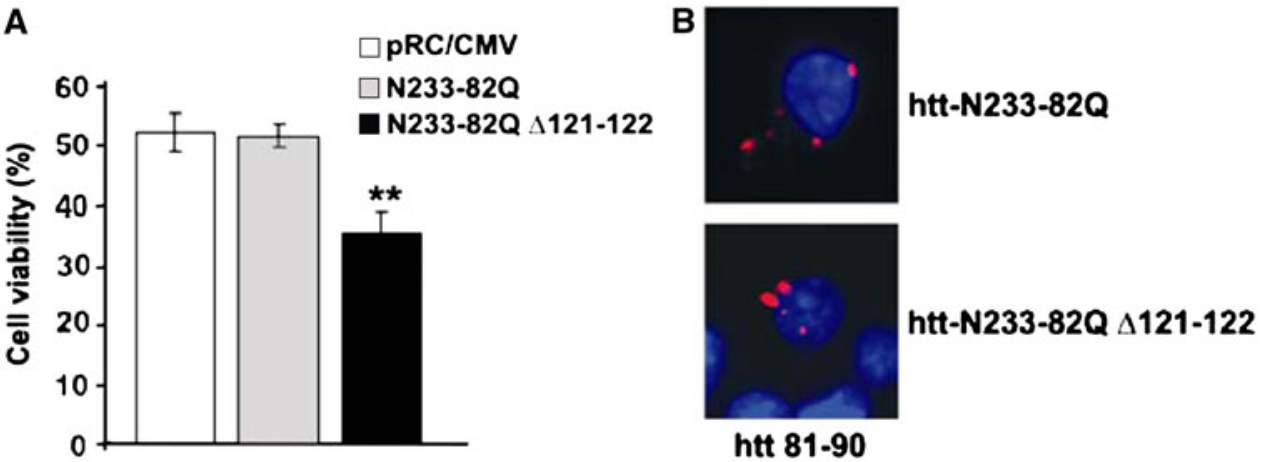

Fig. 6 Cell viability of transfected N2a cells expressing mhtt. a Cell viability of $\mathrm{N} 2 \mathrm{a}$ cells expressing htt-N233-82Q and its mutant httN233-82Q $\Delta 121-122$. Transfection of the empty vector $\mathrm{pRC/CMV}$ served as control. Cell viability was assessed $48 \mathrm{~h}$ after transfection using trypan blue dye solution. In cells expressing the mutant htt-

caspase 3 and caspase 7 activities were significantly higher compared to cells expressing htt-N233-82Q $(1.98 \pm 0.16-$ fold, $n=3$, *** $P<0.001)$. There was no statistically significant difference in caspase activity in cells transfected with vector control, htt-N233-82Q or its mutant htt-N23382Q AA124-125 with reduced efficiency of cleavage. Therefore, we could not determine in this cellular model whether a strong reduction in cleavage fragment release by the mutation AA124-125 results in decreased effector caspase activities. Hence, expression of htt-N233-82Q does not activate apoptotic processes, whereas expression of the mutant htt-N233-82Q $\Delta 121-122$ results in an increased accumulation of $\mathrm{N}$-terminal cleavage fragments and in enhanced caspase 3 and caspase 7 activities which is an advanced event in apoptotic and programmed cell death. Figure $5 \mathrm{~b}$ shows an immunoblot using the antibody $1 \mathrm{C} 2$ detecting htt-N233-82Q and its mutants htt-N233-82Q AA124-125 and htt-N233-82Q $\Delta 121-122$ with either

N233-82Q $\Delta 121-122$ cell viability was $16.5 \%(n=3$, ** $P<0.01)$ reduced compared to cells expressing htt-N233-82Q. b Aggregate formation in $\mathrm{N} 2 \mathrm{a}$ cells expressing either htt-N233-82Q or its mutant htt-N233-82Q $\Delta 121-122$. Aggregates of mhtt are labeled with the antibody htt $81-90$

reduced or increased release of the $\mathrm{N}$-terminal fragment used for luciferase assay. Next, we used a complementary approach to confirm activation of apoptotic processes by detecting the amount of cytochrome c released from mitochondria into the cytosol due to the mutant htt-N233-82Q $\Delta 121-122$. Release of cytochrome c from mitochondria is one of the major initial steps in induction of apoptosis. As shown in Fig. 5c, expression of the mutant htt-N233-82Q $\Delta 121-122$ increased the cytochrome c content in the cytosolic fraction. Quantification of cytochrome $\mathrm{c}$ in the cytosolic fraction of cells expressing the mutant htt-N233-82Q $\Delta 121-122$ revealed that the amount of cytochrome c was $2.4 \pm 0.7$-fold $(n=3)$ higher compared to cells expressing htt-N233-82Q.

Furthermore, we analyzed the viability of neuronal cells transfected with htt-N233-82Q and its mutant htt-N23382Q $\Delta 121-122$ (Fig. 6a). In N2a cells, expressing the mutant htt-N233-82Q $\Delta 121-122$, cell viability was $16.5 \%$ 
reduced compared to cells expressing htt-N233-82Q ( $n=3$, ** $P<0.01)$. There was no statistically significant difference in N2a cell viability between vector control and htt-N233-82Q suggesting that expression of the first 233 aa and appearance of the corresponding $\mathrm{N}$-terminal cleavage product are not toxic. However, N2a cells expressing either htt-N233-82Q or the mutant htt-N233-82Q $\Delta 121-122$ exhibit well-defined inclusion bodies (Fig. 6b).

To study the efficiency of mhtt aggregation, we performed indirect immunofluorescence in transfected COS-7 cells showing intracellular inclusion bodies $48 \mathrm{~h}$ after transfection with htt-N233-82Q and its mutants. Quantitation revealed that approximately $18 \%(n=6)$ of cells transfected with htt-N233-82Q contained at least one microscopic visible aggregate stained with the antibody htt 81-90 (Fig. 7a). In cells expressing the construct htt-N23382Q AA124-125, with decreased N-terminal cleavage fragment release, aggregate formation was significantly reduced to $10 \% \quad(n=6, * P<0.05)$. In contrast to htt-N233-82Q, aggregate frequency was about 2.5-fold higher $(45 \%, n=6, * * * P<0.0001)$ in cells expressing htt-N233-82Q $\Delta 121-122$, a mutant with enhanced cleavage of 2.5 -fold. In addition, we used filter retardation assay with lysates of cells transfected with htt-N233-82Q and indicated mutants (Fig. 7b). As expected, the spot from the mutant htt-N233-82Q $\Delta 121-122$ showed the highest density. The mutants htt-N233-82Q AA124-125 and htt-N23382Q $\Delta 116-125$ did not show a visible reduced density when compared to htt-N233-82Q but this is probably due to a overall low retardation of aggregates from cell lysates.

In conclusion, our data suggest that expression of htt-N233-82Q is not toxic in cell culture. However, the mutation $\Delta 121-122$ within the putative cleavage region enhanced $\mathrm{N}$-terminal cleavage and subsequently aggregation of mhtt
$\mathrm{N}$-terminal fragments. Moreover, activation of apoptotic processes and decreased cell viability is associated with this mutation.

N-Terminal Mhtt with Specific Protein Length Induces Cell Death

We have shown that the expression of htt-N233-82Q in cell culture does not induce apoptotic processes or reduces neuronal cell viability. To analyze if other short htt $\mathrm{N}$-terminal proteins with identical polyglutamine stretches but different protein lengths induce apoptotic processes and cell death, we expressed mhtt with the first 120, 171, and 233 aa in HEK 293 cells to measure effector caspase activity (Fig. 8a). In cells expressing htt-N171-82Q the caspase 3 and caspase 7 activities were significantly higher compared to cells expressing the shorter protein htt-N12082Q $(2.65 \pm 0.56$-fold, $n=3, * * P<0.01)$. There was no statistically significant difference in caspase activity in cells transfected with htt-N120-82Q or htt-N233-82Q compared to the vector control. Expression of the proteins htt-N120-82Q, htt-N171-82Q, and htt-N233-82Q was detected with the antibody N18 (Fig. 8b).

Furthermore, the neuronal cell viability was determined after transfection of N2a cells with these short mhtt constructs (Fig. 8c). Cells expressing htt-N171-82Q showed a reduction of $14.5 \%(n=3, * P<0.05)$ in cell viability compared to cells expressing htt-N120-82Q. There was no statistically significant difference in $\mathrm{N} 2 \mathrm{a}$ cell viability between vector control and htt-N120-82Q or htt-N233-82Q suggesting that expression of mhtt with 171 aa is toxic. However, N2a cells expressing either htt-N120-82Q, htt-N171-82Q or htt-N233-82Q exhibit well-defined inclusion bodies (Figs. 6b, 8d). Quantitation of aggregates

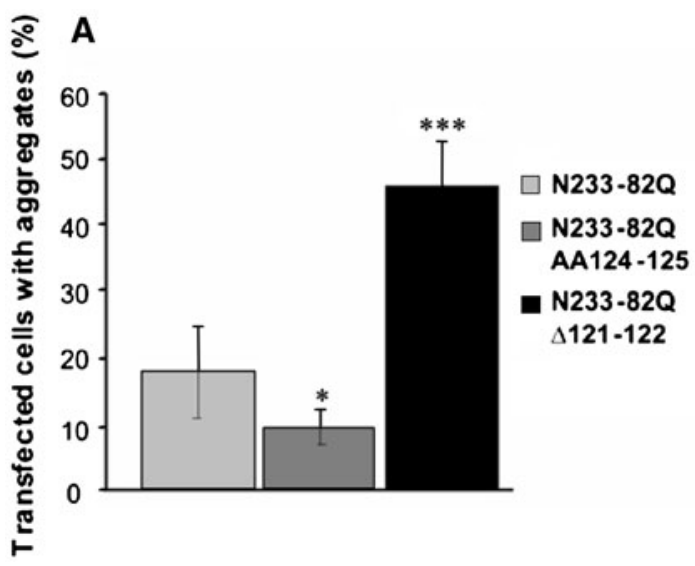

B

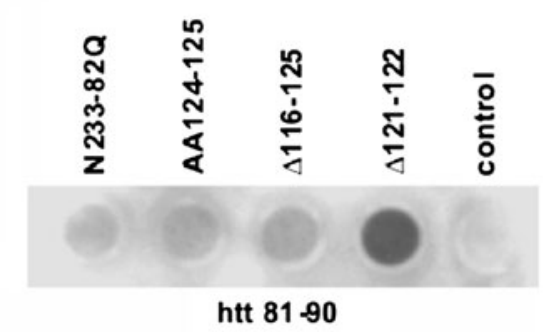

Fig. 7 Aggregation of mhtt fragments. a Quantitation of aggregates in COS-7 cells expressing the indicated mhtt constructs. 200 transfected cells were counted per coverslip in independent experiments $(n=6$, * $P<0.05$; *** $P<0.0001)$. b Aggregate formation was detected by filter retardation assay. Captured protein aggregates from transfected HEK 293 cell lysates were shown using the antibody htt 81-90. An increase of aggregation was observed in cells expressing the mutant htt N233-82Q $\Delta 121-122$. Non-transfection of HEK 293 cells served as a control 

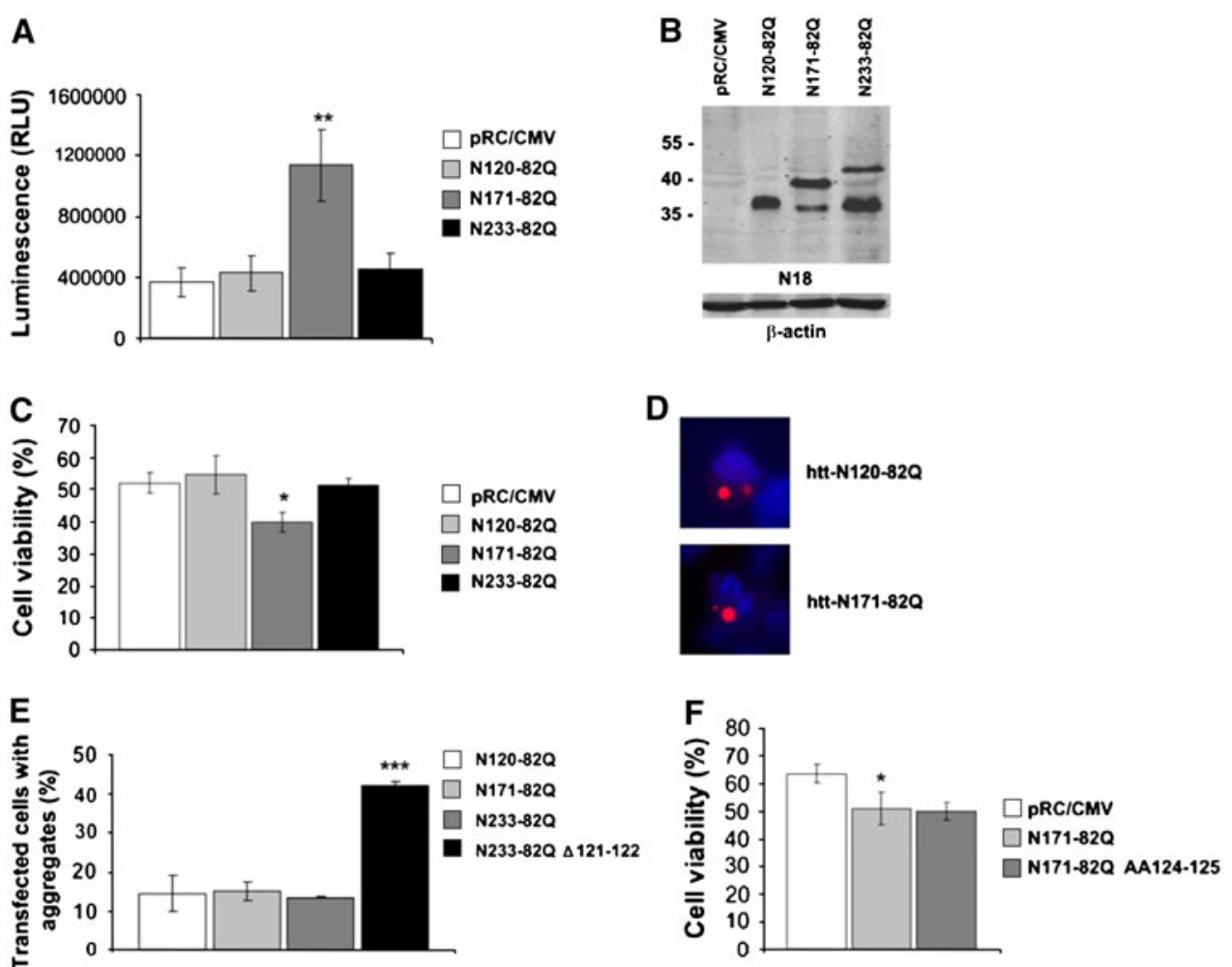

Fig. $8 \mathrm{mhtt}$ of specific size increases apoptotic processes and decreases neuronal cell viability. a Caspase 3 and caspase 7 activities of transfected HEK 293 cells expressing htt-N120-82Q, htt-N171$82 \mathrm{Q}$, and htt-N233-82Q. Transfection of the empty vector $\mathrm{pRC} / \mathrm{CMV}$ served as control. Increased activities of caspase 3 and caspase 7 are demonstrated in increased relative light units (RLU). Luminescence data were obtained $48 \mathrm{~h}$ after transfection. The difference in caspase 3 and caspase 7 activities of cells transfected with htt-N171-82Q was statistically significant compared to htt-N120-82Q $(n=3$, ** $P<0.01$ ). b Immunoblot with the antibody N18 reveals the expression levels of transfected mhtt constructs in HEK 293 cells. c Cell viability of N2a cells expressing either htt-N120-82Q, httN171-82Q or htt-N233-82Q. Transfection of the empty vector $\mathrm{pRC/}$

after expression of htt-N120-82Q, htt-N171-82Q, htt-N233-82Q, and the mutant htt-N233-82Q $\Delta 121-122$ revealed that only the mutant htt-N233-82Q $\Delta 121-122$ shows a significant increase in aggregate formation compared to the vector control (Fig. 8e).

To determine if the AA124-125 substitution in htt-N171-82Q (causing a reduction in fragment release) has an effect on neuronal cell viability, we expressed htt-N17182Q and its mutant htt-N171-82Q AA124-125 in N2a cells (Fig. 8f). There was no statistically significant difference in cell viability between htt-N171-82Q and htt-N171-82Q AA124-125 indicating that expression of mhtt with 171 aa is toxic on its own and a reduction of cleavage fragment without an effect.

These data suggest that the intracellular generation of a specific N-terminal cleavage fragment with a length of approximately 120 aa is not toxic in cell culture. The
CMV served as control. Cell viability was assessed $48 \mathrm{~h}$ after transfection using trypan blue dye solution. In cells expressing htt-N171-82Q cell viability was $14.5 \%(n=3, * P<0.05)$ reduced compared to cells expressing htt-N233-82Q. d Aggregate formation in N2a cells expressing either htt-N120-82Q or htt-N171-82Q. Aggregates of mhtt are labeled with the antibody htt 81-90. e Quantitation of cells containing aggregates stained with the antibody htt 81-90 after expression of the indicated mhtt constructs. 200 transfected cells were counted per coverslip $(n=3$, *** $P<0.001)$. f Cell viability of N2a cells expressing either httN171-82Q or its mutant htt-N171-82Q AA124-125. Transfection of the empty vector $\mathrm{pRC} / \mathrm{CMV}$ served as control $(n=3, * p<0.05)$

htt-N171-82Q protein, previously observed to be toxic in a transgenic mouse model (Schilling et al. 1999), had an effect on neuronal cell viability compared to the proteins htt-N233-82Q and htt-N120-82Q. The toxicity mediated by htt-N171-82Q is not due to an increase in aggregation, since the number of aggregates after expression of mhtt with the first 120, 171, and 233 aa is equal. Thus, our data suggest that mhtt $\mathrm{N}$-terminal fragments of specific size may contribute to mhtt-induced cell death.

\section{Discussion}

Numerous studies provide evidence that specific mhtt $\mathrm{N}$-terminal fragments are toxic to neurons and are sufficient to cause HD (Davies et al. 1997; Graham et al. 2006; Ratovitski et al. 2009; Schilling et al. 1999; Wellington 
et al. 2000; Yu et al. 2003). mhtt fragments of various length have been described in human HD postmortem brain, in mouse models of HD and cell culture systems (DiFiglia et al. 1997; Gafni and Ellerby 2002; Li et al. 2000; Lunkes et al. 2002; Mende-Mueller et al. 2001; Wellington et al. 2000). To further analyze htt proteolytic processing, we developed a cell culture model using transient transfection with DNA expression plasmids encoding the first 171 or 233 aa of htt containing stretches of either 18 or 82 glutamines. In addition to the expressed main htt protein product an approximately $10 \mathrm{kDa}$ smaller htt fragment lacking the epitope aa 115-129 was detected irrespective of htt protein size and length of polyQ by immunoblot analysis. In comparison, the cleaved N-terminal fragment that was identified in the transgenic mouse model of HD expressing htt-N171-82Q is running at the same molecular size on SDS-PAGE as htt-N120-82Q and the cleavage fragment from htt-N233-82Q expressed in HEK 293 cells suggesting that cleavage in vitro and in vivo is around aa 120. Furthermore, this N-terminal cleavage band was detected on immunoblot after expression of htt$\mathrm{N} 233-82 \mathrm{Q}$ in non-neuronal and neuronal cell lines. It is likely that identical proteases act in the various cell lines. We cannot rule out that this particular cleavage band consists of several similar sized fragments, which are not separable on SDS-PAGE or that the cleavage event varies in different cell types by only one or a few amino acids.

The size of the mhtt N-terminal fragment described in this study is much smaller than the fragments generated by caspases or calpains (Gafni et al. 2004; Graham et al. 2006; Wellington et al. 2000). YAC128 mice expressing fulllength mhtt that has become resistant to caspase 6 cleavage by mutation of aa 586 are protected against behavioural and neuropathological features of HD (Graham et al. 2006). This suggests that caspase 6 cleavage of mhtt is a critical initial cleavage following further fragmentation of mhtt and development of HD in mice. However, in a different study caspase inhibitors did not prevent further cleavage into smaller $\mathrm{N}$-terminal fragments in a PC12 cell culture model (Ratovitski et al. 2007). In this study, we could demonstrate generation of short $\mathrm{N}$-terminal fragments after expression of truncated htt proteins with either 171 or 233 aa independent of previous caspase cleavage.

The fragment identified in this study is comparable in size to the cp-A cleavage product found in the nucleus and generated by cleavage between epitope 1-82 and epitope 115-129 in NG108-15 cells expressing full-length mhtt with 116Q (Lunkes et al. 2002). In addition, the fragment is of comparable size to the fragment detected in mice expressing full-length mhtt with $148 \mathrm{Q}$ taking the different polyQ lengths into account (Tanaka et al. 2006). Lunkes et al. detected a second htt fragment, termed cp-B, which was found to be predominantly in the cytoplasm and can be released by cleavage between aa 115-129 and aa 214-229. In our cell culture model expressing truncated htt questions concerning the cp-B fragment cannot be addressed since only one fragment of similar size as cp-A is detectable. Hence, our cell model expressing truncated htt is a good opportunity to analyze the effect of one specific $\mathrm{N}$-terminal cleavage fragment only without the potential obscuring effect of additional fragments. Indirect immunofluorescence studies with transfected cells expressing htt-N233$82 \mathrm{Q}$ showed that the $\mathrm{N}$-terminal cleavage product, which is detectable with the antibody htt 81-90 but not with the antibody htt $115-129$, is located in the perinuclear region and the nucleus. It cannot be excluded that both uncleaved htt-N233-82Q protein and the N-terminal cleavage fragment form mixed aggregates in the perinuclear and nuclear region detectable with the antibodies htt 81-90 and htt 115-129. These findings are consistent with our previous data demonstrating N-terminal proteolytic cleavage between aa 81-90 and aa 115-129 generating N-terminal fragments accumulating in the nuclei of neurons in the cortex of human HD postmortem brain and in the tissue of HD N171-82Q mouse brain (Schilling et al. 2007). Others have also shown that not only small $\mathrm{N}$-terminal fragments, such as cp-A, but also larger caspase-derived N-terminal htt fragments enter the nucleus (Sawa et al. 2005; Warby et al. 2008a). Neurotoxicity may reflect nuclear translocation and aberrant protein interactions of mhtt N-terminal fragments with interactors such as Sp1 (Dunah et al. 2002), p53, and CREB binding protein (CBP) (Nucifora et al. 2001; Steffan et al. 2000).

Our mutagenesis studies demonstrated that the region aa $116-125$ is important for cleavage efficiency. We discovered different mutations that caused either strongly enhanced or reduced cleavage. On the other hand, a definite cleavage site could not be located this way and it is not clear whether the involved protease(s) only recognize the substrate htt between aa 116-125 or even cleave within this specific region. Furthermore, it is possible that a protease cleaves within this region and acts on more than one site as reported for the $\gamma$-secretase in Alzheimer's disease (Mattson 2004) or that the region is accessible for more than one protease. Sequence-based structural predictions suggest that full-length htt contains four HEAT domains and four proteolytic susceptible PEST domains (Andrade and Bork 1995; Rechsteiner and Rogers 1996; Takano and Gusella 2002). PEST domain 2 with cleavage sites for caspases and calpains is well characterized. However, the region between aa 116-125 is located in the predicted PEST domain 1 and thus most likely accessible for proteases.

The mutations $\Delta 116-125$, AA124-125, and $\Delta 121-122$ within the putative cleavage region affect the cleavage efficiency with either reduced or increased fragment release. There was no internal mutation totally preventing 
$\mathrm{N}$-terminal fragment generation and therefore mutations may result in cleavage at alternative sites. Moreover, cleavage efficiency might be mediated by post-translational modification as was previously shown by phosphorylation of S421 causing reduced htt cleavage by caspase 6 (Warby et al. 2008b). We cannot exclude that mutations within the putative cleavage region may alter the post-translational modification of htt protein resulting in modulation of cleavage efficiency or protein stability of $\mathrm{N}$-terminal fragments.

Our analysis of cells expressing htt-N233-82Q and its mutants revealed that expression of htt-N233-82Q alone does not exhibit any toxicity measured by caspase 3 and caspase 7 activities, cytochrome c release and neuronal cell death rate. Therefore, a reduction in cleavage fragment release by the mutation AA124-125 has thus no effect, although the mutation AA124-125 reduces mhtt aggregation significantly. In contrast, the mutant htt-N233-82Q $\Delta 121-122$ is associated with activation of apoptotic processes, neuronal cell death and increased aggregation. There is the possibility that the toxic effect of $\Delta 121-122$ is not due to the enhanced cleavage of htt-N233-82Q. The specific mutation $\Delta 121-122$ could alter the $\mathrm{N}$-terminal fragment stability or the protein conformation with a subsequent impact of interaction with other cellular proteins. $\Delta 121-122$ may also influence the $\mathrm{N}$-terminal htt cleavage site, whereas a new C-terminus is generated leading to an alternative toxic fragment.

The R6/2 and N171-82Q mouse models of HD expressing short $\mathrm{N}$-terminal fragments of mhtt produce a severe phenotype of $\mathrm{HD}$ indicating that mhtt $\mathrm{N}$-terminal fragments are toxic in vivo (Mangiarini et al. 1996; Schilling et al. 1999). Interestingly, an HD mouse model expressing the first 117 aa of mhtt did not show an HD phenotype despite neuronal inclusions (Slow et al. 2005). Previously, it was shown that htt can be endogenously cleaved at aa 167 releasing an $\mathrm{N}$-terminal fragment named cp-2 (distinct from cp-B). Deletion of the cp-2 site almost completely prevents mhtt (N511-52Q) induced toxicity in neuronal HT22 cells suggesting that this specific fragment is toxic (Ratovitski et al. 2009). In this study, we compared the toxicity of mhtt proteins with different protein size and identical polyglutamine lengths by measurement of effector caspase activities and neuronal cell viability. Our results demonstrate that htt-N171-82Q is toxic in cells compared to htt-N233-82Q and htt-N120-82Q. All of this data suggest that cellular toxicity is mediated by mhtt $\mathrm{N}$-terminal fragments of specific size. For example, the processing of the amyloid precurser protein (APP) by the $\gamma$-secretase generates the Aß42- and AB40-peptides, whereas the Aß42-peptide is more toxic in vivo suggesting that a difference in two aa mediates toxicity (Iijima et al. 2004). Further investigation of the mechanisms by which
N-terminal fragments of specific size induce toxicity should help to understand the underlying molecular pathways in HD.

Acknowledgment We thank Marcy MacDonald for providing ST $H d h^{+} / H d h^{+}$cells. This work was supported by the Hereditary Disease Foundation.

Open Access This article is distributed under the terms of the Creative Commons Attribution Noncommercial License which permits any noncommercial use, distribution, and reproduction in any medium, provided the original author(s) and source are credited.

\section{References}

Andrade MA, Bork P (1995) HEAT repeats in the Huntington's disease protein. Nat Genet 11:115-116

Arrasate M, Mitra S, Schweitzer ES, Segal MR, Finkbeiner S (2004) Inclusion body formation reduces levels of mutant huntingtin and the risk of neuronal death. Nature 431:805-810

Davies SW, Turmaine M, Cozens BA, DiFiglia M, Sharp AH, Ross CA, Scherzinger E, Wanker EE, Mangiarini L, Bates GP (1997) Formation of neuronal intranuclear inclusions underlies the neurological dysfunction in mice transgenic for the HD mutation. Cell 90:537-548

DiFiglia M, Sapp E, Chase KO, Davies SW, Bates GP, Vonsattel JP, Aronin N (1997) Aggregation of huntingtin in neuronal intranuclear inclusions and dystrophic neurites in brain. Science 277:1990-1993

Dunah AW, Jeong H, Griffin A, Kim YM, Standaert DG, Hersch SM, Mouradian MM, Young AB, Tanese N, Krainc D (2002) Sp1 and TAFII130 transcriptional activity disrupted in early Huntington's disease. Science 296:2238-2243

Gafni J, Ellerby LM (2002) Calpain activation in Huntington's disease. J Neurosci 22:4842-4849

Gafni J, Hermel E, Young JE, Wellington CL, Hayden MR, Ellerby LM (2004) Inhibition of calpain cleavage of huntingtin reduces toxicity: accumulation of calpain/caspase fragments in the nucleus. J Biol Chem 279:20211-20220

Goldberg YP, Nicholson DW, Rasper DM, Kalchman MA, Koide HB, Graham RK, Bromm M, Kazemi-Esfarjani P, Thornberry NA, Vaillancourt JP, Hayden MR (1996) Cleavage of huntingtin by apopain, a proapoptotic cysteine protease, is modulated by the polyglutamine tract. Nat Genet 13:442-449

Graham RK, Deng Y, Slow EJ, Haigh B, Bissada N, Lu G, Pearson J, Shehadeh J, Bertram L, Murphy Z, Warby SC, Doty CN, Roy S, Wellington CL, Leavitt BR, Raymond LA, Nicholson DW, Hayden MR (2006) Cleavage at the caspase-6 site is required for neuronal dysfunction and degeneration due to mutant huntingtin. Cell 125:1179-1191

Gutekunst CA, Li SH, Yi H, Mulroy JS, Kuemmerle S, Jones R, Rye D, Ferrante RJ, Hersch SM, Li XJ (1999) Nuclear and neuropil aggregates in Huntington's disease: relationship to neuropathology. J Neurosci 19:2522-2534

Hodgson JG, Agopyan N, Gutekunst CA, Leavitt BR, LePiane F, Singaraja R, Smith DJ, Bissada N, McCutcheon K, Nasir J, Jamot L, Li XJ, Stevens ME, Rosemond E, Roder JC, Phillips AG, Rubin EM, Hersch SM, Hayden MR (1999) A YAC mouse model for Huntington's disease with full-length mutant huntingtin, cytoplasmic toxicity, and selective striatal neurodegeneration. Neuron 23:181-192 
Iijima K, Liu HP, Chiang AS, Hearn SA, Konsolaki M, Zhong Y (2004) Dissecting the pathological effects of human Abeta40 and Abeta42 in Drosophila: a potential model for Alzheimer's disease. Proc Natl Acad Sci USA 101:6623-6628

Kim YJ, Yi Y, Sapp E, Wang Y, Cuiffo B, Kegel KB, Qin ZH, Aronin N, DiFiglia M (2001) Caspase 3-cleaved N-terminal fragments of wild-type and mutant huntingtin are present in normal and Huntington's disease brains, associate with membranes, and undergo calpain-dependent proteolysis. Proc Natl Acad Sci USA 98:12784-12789

Kim YJ, Sapp E, Cuiffo BG, Sobin L, Yoder J, Kegel KB, Qin ZH, Detloff P, Aronin N, DiFiglia M (2006) Lysosomal proteases are involved in generation of N-terminal huntingtin fragments. Neurobiol Dis 22:346-356

Kuemmerle S, Gutekunst CA, Klein AM, Li XJ, Li SH, Beal MF, Hersch SM, Ferrante RJ (1999) Huntington aggregates may not predict neuronal death in Huntington's disease. Ann Neurol 46:842-849

Landles C, Sathasivam K, Weiss A, Woodman B, Moffitt H, Finkbeiner S, Sun B, Gafni J, Ellerby LM, Trottier Y, Richards WG, Osmand A, Paganetti P, Bates GP (2010) Proteolysis of mutant huntingtin produces an exon 1 fragment that accumulates as an aggregated protein in neuronal nuclei in Huntington disease. J Biol Chem 285:8808-8823

Li H, Li SH, Johnston H, Shelbourne PF, Li XJ (2000) Aminoterminal fragments of mutant huntingtin show selective accumulation in striatal neurons and synaptic toxicity. Nat Genet 25:385-389

Lunkes A, Lindenberg KS, Ben-Haiem L, Weber C, Devys D, Landwehrmeyer GB, Mandel JL, Trottier Y (2002) Proteases acting on mutant huntingtin generate cleaved products that differentially build up cytoplasmic and nuclear inclusions. Mol Cell 10:259-269

Mangiarini LSK, Seller M, Cozens B, Harper A, Hetherington C, Lawton M, Trottier Y, Lehrach H, Davies SW, Bates GP (1996) Exon 1 of the HD gene with an expanded CAG repeat is sufficient to cause a progressive neurological phenotype in transgenic mice. Cell 87:493-506

Mattson MP (2004) Pathways towards and away from Alzheimer's disease. Nature 430:631-639

Mende-Mueller LM, Toneff T, Hwang SR, Chesselet MF, Hook VY (2001) Tissue-specific proteolysis of Huntingtin (htt) in human brain: evidence of enhanced levels of $\mathrm{N}$ - and $\mathrm{C}$-terminal htt fragments in Huntington's disease striatum. J Neurosci 21:1830-1837

Miller JP, Holcomb J, Al-Ramahi I, de Haro M, Gafni J, Zhang N, Kim E, Sanhueza M, Torcassi C, Kwak S, Botas J, Hughes RE, Ellerby LM (2010) Matrix metalloproteinases are modifiers of huntingtin proteolysis and toxicity in Huntington's disease. Neuron 67:199-212

Nucifora FC Jr, Sasaki M, Peters MF, Huang H, Cooper JK, Yamada M, Takahashi H, Tsuji S, Troncoso J, Dawson VL, Dawson TM, Ross CA (2001) Interference by huntingtin and atrophin-1 with cbp-mediated transcription leading to cellular toxicity. Science 291:2423-2428

Ratovitski T, Nakamura M, D'Ambola J, Chighladze E, Liang Y, Wang W, Graham R, Hayden MR, Borchelt DR, Hirschhorn RR, Ross CA (2007) N-terminal proteolysis of full-length mutant huntingtin in an inducible PC12 cell model of Huntington's disease. Cell Cycle 6:2970-2981

Ratovitski T, Gucek M, Jiang H, Chighladze E, Waldron E, D'Ambola J, Hou Z, Liang Y, Poirer MA, Hirschhorn RR, Graham R, Hayden MR, Cole RN, Ross CA (2009) Mutant Huntingtin $\mathrm{N}$-terminal fragments of specific size mediate aggregation and toxicity in neuronal cells. J Biol Chem 284:10855-10867
Rechsteiner M, Rogers SW (1996) PEST sequences and regulation by proteolysis. Trends Biochem Sci 21:267-271

Reddy PH, Williams M, Charles V, Garrett L, Pike-Buchanan L, Whetsell WO Jr, Miller G, Tagle DA (1998) Behavioural abnormalities and selective neuronal loss in HD transgenic mice expressing mutated full-length $\mathrm{HD}$ cDNA. Nat Genet 20:198-202

Ross CA, Becher MW, Colomer V, Engelender S, Wood JD, Sharp AH (1997) Huntington's disease and dentatorubral-pallidoluysian atrophy: proteins, pathogenesis and pathology. Brain Pathol 7:1003-1016

Ross CA, Poirier MA (2005) Opinion: what is the role of protein aggregation in neurodegeneration? Nat Rev Mol Cell Biol 6:891-898

Sanchez I, Mahlke C, Yuan J (2003) Pivotal role of oligomerization in expanded polyglutamine neurodegenerative disorders. Nature 421:373-379

Saudou F, Finkbeiner S, Devys D, Greenberg ME (1998) Huntingtin acts in the nucleus to induce apoptosis but death does not correlate with the formation of intranuclear inclusions. Cell 95:55-66

Sawa A, Nagata E, Sutcliffe S, Dulloor P, Cascio MB, Ozeki Y, Roy S, Ross CA, Snyder SH (2005) Huntingtin is cleaved by caspases in the cytoplasm and translocated to the nucleus via perinuclear sites in Huntington's disease patient lymphoblasts. Neurobiol Dis 20:267-274

Schilling G, Becher MW, Sharp AH, Jinnah HA, Duan K, Kotzuk JA, Slunt HH, Ratovitski T, Cooper JK, Jenkins NA, Copeland NG, Price DL, Ross CA, Borchelt DR (1999) Intranuclear inclusions and neuritic aggregates in transgenic mice expressing a mutant $\mathrm{N}$-terminal fragment of huntingtin. Hum Mol Genet 8:397-407

Schilling G, Klevytska A, Tebbenkamp AT, Juenemann K, Cooper J, Gonzales V, Slunt H, Poirer M, Ross CA, Borchelt DR (2007) Characterization of huntingtin pathologic fragments in human Huntington disease, transgenic mice, and cell models. J Neuropathol Exp Neurol 66:313-320

Sharp AH, Loev SJ, Schilling G, Li SH, Li XJ, Bao J, Wagster MV, Kotzuk JA, Steiner JP, Lo A et al (1995) Widespread expression of Huntington's disease gene (IT15) protein product. Neuron 14:1065-1074

Slow EJ, Graham RK, Osmand AP, Devon RS, Lu G, Deng Y, Pearson J, Vaid K, Bissada N, Wetzel R, Leavitt BR, Hayden MR (2005) Absence of behavioral abnormalities and neurodegeneration in vivo despite widespread neuronal huntingtin inclusions. Proc Natl Acad Sci U S A 102:11402-11407

Steffan JS, Kazantsev A, Spasic-Boskovic O, Greenwald M, Zhu YZ, Gohler H, Wanker EE, Bates GP, Housman DE, Thompson LM (2000) The Huntington's disease protein interacts with p53 and CREB-binding protein and represses transcription. Proc Natl Acad Sci U S A 97:6763-6768

Takano H, Gusella JF (2002) The predominantly HEAT-like motif structure of huntingtin and its association and coincident nuclear entry with dorsal, an NF-kB/Rel/dorsal family transcription factor. BMC Neurosci 3:15

Tanaka Y, Igarashi S, Nakamura M, Gafni J, Torcassi C, Schilling G, Crippen D, Wood JD, Sawa A, Jenkins NA, Copeland NG, Borchelt DR, Ross CA, Ellerby LM (2006) Progressive phenotype and nuclear accumulation of an amino-terminal cleavage fragment in a transgenic mouse model with inducible expression of full-length mutant huntingtin. Neurobiol Dis 21:381-391

The Huntington's Disease Collaborative Research Group (1993) A novel gene containing a trinucleotide repeat that is expanded and unstable on Huntington's disease chromosomes. The Huntington's Disease Collaborative Research Group. Cell 72:971-983

Trettel F, Rigamonti D, Hilditch-Maguire P, Wheeler VC, Sharp AH, Persichetti F, Cattaneo E, MacDonald ME (2000) Dominant 
phenotypes produced by the HD mutation in $\operatorname{STHdh}(\mathrm{Q} 111)$ striatal cells. Hum Mol Genet 9:2799-2809

Vonsattel JP, DiFiglia M (1998) Huntington disease. J Neuropathol Exp Neurol 57:369-384

Vonsattel JP, Myers RH, Stevens TJ, Ferrante RJ, Bird ED, Richardson EP Jr (1985) Neuropathological classification of Huntington's disease. J Neuropathol Exp Neurol 44:559-577

Warby SC, Doty CN, Graham RK, Carroll JB, Yang YZ, Singaraja RR, Overall CM, Hayden MR (2008a) Activated caspase-6 and caspase-6-cleaved fragments of huntingtin specifically colocalize in the nucleus. Hum Mol Genet 17(15):2390-2404

Warby SC, Doty CN, Graham RK, Shively J, Singaraja RR, Hayden MR (2008b) Phosphorylation of huntingtin reduces the accumulation of its nuclear fragments. Mol Cell Neurosci 40:121-127

Wellington CL, Singaraja R, Ellerby L, Savill J, Roy S, Leavitt B, Cattaneo E, Hackam A, Sharp A, Thornberry N, Nicholson DW, Bredesen DE, Hayden MR (2000) Inhibiting caspase cleavage of huntingtin reduces toxicity and aggregate formation in neuronal and nonneuronal cells. J Biol Chem 275:19831-19838

Wellington CL, Ellerby LM, Gutekunst CA, Rogers D, Warby S, Graham RK, Loubser O, van Raamsdonk J, Singaraja R, Yang YZ, Gafni J, Bredesen D, Hersch SM, Leavitt BR, Roy S, Nicholson DW, Hayden MR (2002) Caspase cleavage of mutant huntingtin precedes neurodegeneration in Huntington's disease. J Neurosci 22:7862-7872

Wheeler VC, White JK, Gutekunst CA, Vrbanac V, Weaver M, Li XJ, Li SH, Yi H, Vonsattel JP, Gusella JF, Hersch S, Auerbach W, Joyner AL, MacDonald ME (2000) Long glutamine tracts cause nuclear localization of a novel form of huntingtin in medium spiny striatal neurons in HdhQ92 and HdhQ111 knock-in mice. Hum Mol Genet 9:503-513

Yu ZX, Li SH, Evans J, Pillarisetti A, Li H, Li XJ (2003) Mutant huntingtin causes context-dependent neurodegeneration in mice with Huntington's disease. J Neurosci 23:2193-2202 